\title{
A ESCUTA MUSICAL DE ESTUDANTES DE MÚSICA EM SMARTPHONES
}

\section{José Ruy Henderson Filho Juliana do Rêgo Medeiros UEPA}

\section{Resumo}

O presente trabalho apresenta uma investigação sobre o processo de escuta musical em smartphones. Tem como foco alunos do Curso de Licenciatura em Música e visa compreender como estudantes de música realizam suas escutas musicais por meio de smartphones. A pesquisa é um desdobramento e ao mesmo tempo aprofundamento de questões abordadas em outra pesquisa, desenvolvida por meio do Programa de Iniciação Científica (PIBIC), que fez um levantamento mais amplo sobre tal processo. Desta vez, no entanto, realiza-se um estudo de casos, buscando responder a questões referentes às funções da escuta musical em smartphones e a relação da escuta musical com a formação recebida no curso de licenciatura. A investigação foi realizada com três alunos do Curso de Licenciatura em Música da Universidade do Estado do Pará e para a coleta dos dados utilizouse as entrevistas semiestruturadas, que após sua conclusão, foram todas devidamente transcritas e analisadas. A pesquisa encontra-se concluída.

\section{Palavras-chave:}

Escuta musical; Smartphones;

Licenciatura em música.

\section{INTRODUÇÃO}

Os avanços científicos e tecnológicos modificaram gerações e relações, e no cenário musical os acontecimentos relacionados a esses avanços foram marcantes e modificaram a forma como o homem se relaciona com a música.

Em 1877, o cientista norte-americano Thomas Edison inventou o fonógrafo, o primeiro aparato capaz de gravar e reproduzir a fala humana. Esse aparelho deu início à evolução da indústria fonográfica, entretanto possuía alguns limites,

\section{Abstract}

This paper presents an investigation about the process of listening to music on smartphones. It focuses on students of the Licenciatura Course in Music and aims to understand how music students perform their listening through smartphones. The research is an unfolding and at the same time deepening of issues addressed in another research, developed through the Program of Scientific Initiation (PIBIC), which made a broader survey on this process. This time, however, a case study is conducted, seeking to answer questions related to the functions of listening to music on smartphones and the relationship of listening to music with the training received in the undergraduate course. The research was carried out with three students of the Licentiate Course in Music of the State University of Pará and for the collection of the data the semistructured interviews were used, which, after their conclusion, were all properly transcribed and analyzed. The search is complete.

Keywords:

Musical listening; Smartphones; Degree in music.

como a impossibilidade de realizar cópia das gravações que eram registradas em cilindros de cera. Após o fonógrafo o gramofone surgiu como um avanço que trouxe a introdução dos discos em substituição aos cilindros (GOMES, 2014).

Os avanços seguiram e por volta da década de 1920 "[...] a indústria fonográfica passou por uma série de transformações acarretadas pelo advento do rádio e pela substituição da gravação mecânica pela gravação elétrica [...]" (GOMES, 2014, p. 76). 
Com essas transformações, surgiu o vinil (no ano de 1940), seguido pelo surgimento das fitas magnéticas e chegando às mídias digitais que modificaram ainda mais o cenário musical. Nesse cenário, com o surgimento do CD (Compact Disc) em 1980, houve a possibilidade de se ampliar a capacidade de armazenamento de músicas.

Em 1987 surge o mp3, que foi "[...] inicialmente criado com a intenção de comprimir o áudio para possibilitar a transmissão pelas redes de dados limitadas em velocidade" (HENDERSON FILHO, 2016, p. 302). Esse formato de arquivo iniciou um processo revolucionário na escuta musical, associado ao crescimento, nos anos seguintes, da internet e das conexões cada vez mais velozes.

Com o surgimento de celulares capazes de reproduzir música, deu-se início a uma nova era da escuta musical, entretanto, atualmente falase muito mais dos smartphones, os telefones inteligentes (MERIJE, 2012).

É comum presenciarmos cenas do cotidiano em que as pessoas estejam com fones de ouvido: caminhando, em uma viagem de ônibus, de avião, na sala de espera de clínicas e hospitais, na sala de aula, e em muitos outros espaços e momentos. (HENDERSON FILHO, 2016, p. 302).

Essas cenas se tornam cada vez mais comuns e partindo desta observação de que a popularização dos smartphones configurou um novo cenário da escuta musical para todos, foi elaborado um projeto para o Programa Institucional de Bolsa de Iniciação Científica (PIBIC) intitulado "Música móbile: um estudo sobre a escuta musical de estudantes de música em smartphones", este projeto realizado no período de agosto de 2016 a junho de 2017, teve como interesse investigar o que essas pessoas tão conectadas a seus celulares escutam, como escutam, que tipos de músicas escutam e qual a função dessa escuta.

Com base nesse estudo e nos dados levantados pela pesquisa (Cf. HENDERSON FILHO; MEDEIROS, 2017) é que surge a presente investigação, visando o aprofundamento da primeira ao levantar a seguinte questão: Como os alunos do Curso de Licenciatura em Música da Universidade do Estado do Pará (UEPA) realizam a escuta musical em smartphones?
A presente investigação apresenta como objetivo geral compreender como se processa a escuta musical de jovens estudantes de música por meio de smartphones. Como objetivos específicos busca: identificar as funções da escuta musical em smartphones e investigar se existe relação da escuta musical com a formação recebida no curso de Licenciatura em Música da UEPA.

Esta pesquisa se justifica por sua busca em compreender o processo da escuta musical de músicos em smartphones, considerando que estes aparelhos tem adquirido um espaço significante na vida das pessoas.

Não é difícil encontrar evidências do grande valor que a música tem para as pessoas. O difícil é explicar por que as pessoas gostam de ouvir música [...]. Os significados atribuídos à música na relação de audição podem estar vinculados a diferentes aspectos [...]. (SANTOS, 2007, p. 34).

Hoje, grande parte dos brasileiros já possui um aparelho smartphone, que são aqueles que "apresentam-se como uma tecnologia que reúne várias mídias num só aparelho (telefone, internet, televisão, console de jogos, recursos de computadores pessoais)" (MERIJE, 2012, p. 36). Assim como cada aparelho tecnológico criado a partir do fonógrafo (1877) teve sua importância para a área da escuta musical, é de importância investigar a escuta musical em um novo degrau da evolução, sendo este os aparelhos smartphones.

\section{A METODOLOGIA DA PESQUISA}

O trabalho aqui exposto abrangeu em sua primeira etapa a pesquisa bibliográfica e para sua realização foi utilizado o método de pesquisa de Estudo de Caso. A mesma foi realizada com três alunos, sendo um aluno de cada turma $\left(4^{\circ}\right.$ semestre, $6^{\circ}$ semestre e $8^{\circ}$ semestre) do Curso de Licenciatura em Música da Universidade do Estado do Pará. Os alunos foram selecionados a partir de dados levantados e analisados da pesquisa para o PIBIC. Para a coleta de dados foi utilizada a entrevista que consiste em "[...] uma técnica de pesquisa para coleta de informações, dados e evidências cujo objetivo básico é entender e compreender o significado que entrevistados atribuem a questões e situações [...]." (MARTINS; THEÓPHILO, 2009, p. 88). 
A entrevista citada para a utilização nesta pesquisa foi a do tipo semiestruturada, que é conduzida por um roteiro, entretanto apresenta a liberdade de serem acrescentadas novas perguntas ou questões pelo entrevistador. A partir da elaboração do roteiro necessário para a aplicação das entrevistas, foram realizadas as mesmas com estudantes aqui intitulados de Estudante 1, Estudante 2 e Estudante 3.

\section{OS RESULTADOS DA PESQUISA}

Todos podemos nos relacionar com a música de diversas formas, tais como: a apreciação, as atividades de performance ou através do processo de criação musical. Entretanto segundo Silva e Barbosa (2017, p. 3): "[...] a escuta é, sem dúvida, a primeira e mais importante ferramenta de contato [...]."

Sabemos que a escuta musical é uma ação natural tanto para músicos como para não músicos e essa ação apresenta uma função, uma finalidade. A respeito das funções da escuta musical dos entrevistados, foram citadas as funções: aprender, apreciar (aspecto sonoro) e relaxar (função de expressão emocional). O Estudante 1 afirma escutar música para aprender:

\footnotetext{
Participo de várias bandas, são muitas músicas, vai ter uma hora em que eu não vou conseguir gravar tudo e memorizar, existem dias que eu ensaio com três, quatro bandas diferentes, com a última banda eu já estou indo tocando no automático, quando eu estou no estúdio há mais de seis horas ensaiando com várias bandas às vezes eu acabo esquecendo determinado padrão, ritmo e curva, determinada manulação, acentuação, textura, introdução da música, eu acabo esquecendo o arranjo. No celular, já está gravado o que eu estou fazendo ou eu gravo o que eu vou fazer, [...] eu chego em casa e vejo o que eu fiz, pra poder estar desenvolvendo sempre [...] a minha função na banda que eu estou trabalhando [...]. (ESTUDANTE 1, 26/10/2017).
}

Observa-se através da resposta o uso da escuta musical como meio de aprendizagem. Para a Estudante 2 a escuta tem o foco na apreciação das músicas, e diz:

Eu faço download das músicas [...] boa parte [...] algumas é possível, outras não, porque nem todas as músicas tem gravação, muitas foram cantadas e não foram gravadas ou mesmo não apresentam uma gravação boa, então eu nem faço o download. [...] eu não ouço para aprender, ouço para apreciar [...]. (ESTUDANTE 2, 27/10/2017).
Essa resposta está diretamente ligada ao som, aos aspectos sonoros. Segundo Santos (2007): "[...] os aspectos sonoros referentes às qualidades intrínsecas do som - timbre, densidade, altura, intensidade - e da música ritmo, melodia, harmonia, andamento - são menos citados" por alunos quando indagados a respeito do 'porque ouvir música' "do que as unidades de análise da categoria 'estados emocionais' [...]". (SANTOS, 2007, p. 71).

O Estudante 3 afirma ter sua escuta musical centrada no relaxamento e apresenta e escuta musical como:

[...] uma verdadeira terapia, porque, por exemplo, no ônibus quando eu ouço uma música é uma forma de me distanciar um pouco da situação que acontece ali, o congestionamento, ônibus lotado, então a música para mim, assim, a escuta da música é mais uma [...] terapia, um prazer [...]. (ESTUDANTE 3, 27/10/2017).

Esta resposta se configura como função de expressão emocional (SANTOS, 2007), essa função consiste na ideia de que a expressão e o extravasamento de ideias e emoções fazem parte da música. A respeito do caráter terapêutico da música, sabemos que diversos sentimentos, sensações e estados de espírito são sentidos através da música, isso evidencia “[...] a existência de uma função de caráter [...] terapêutico exercida pela escuta musical" (SANTOS, 2007, p. 58).

Ao investigar a função da escuta musical e relacionar com atividades de aprendizagem vivenciadas ao longo de suas vidas, os entrevistados afirmaram utilizar para: aprender músicas que serão executadas em seu trabalho como músico baterista (Estudante 1), utiliza para aprender e observar técnicas tanto de cantores como instrumentistas (Estudante 2) eter realizado a utilização para aprender músicas em inglês trabalhando a pronuncia da língua nas músicas (Estudante 3).

\section{A RELAÇÃO DA ESCUTA MUSICAL COM A FORMAÇÃO RECEBIDA NO CURSO DE LICENCIATURA EM MÚSICA DA UEPA}

Neste tópico, foi inserida nas entrevistas a discussão a respeito do uso dos celulares em sala de aula. Foi questionado se em algum momento dentro da vivência individual de cada 
aluno, houve a utilização da escuta musical no smartphone em/para alguma matéria do curso de licenciatura e todos os estudantes responderam que já utilizaram em algum momento do curso.

O Estudante 1 se encontra no 8) semestre e destacou o uso da escuta musical no seu smartphone para o trabalho em campo da matéria "Estágio supervisionado I" e completou:

Nessa disciplina, estágio, eu me vi tendo que aprender músicas muito rapidamente pra desenvolver nas aulas e talvez a professora do meu estágio até confiando muito em mim, só me disse "olha, a música que você vai tocar é essa e amanhã eu quero que você traga ela assim e assim", eu nem dominava tanto e nem conhecia a música, o que eu fiz? Recorri ao Youtube, procurei a música, depois recorri a um outro site onde tinha as cifras da música, aprendi a música, quando cheguei na sala de aula a professora queria que a música fosse tocada em outro tom, o que não foi dificuldade em um primeiro momento, porque eu já tinha estudado violão, [...] o problema foi realmente cantar, ela pediu que eu cantasse e mudasse o tom, só que eu não sou um cantor de fato, eu estudo canto pro curso de música, [...] então eu falei "olha professora, eu não sei se eu vou conseguir cantar, porque não é o meu tom de música, eu não estou acostumado". Na verdade era uma situação em que eu estava treinado pra tocar naquele tom que eu aprendi através do Youtube e do site onde tinham as cifras, então ela disse: "toca assim, aí a gente vai cantar, eu vou cantar e você vai aprender", eu tive a sacada de já usar o celular gravando um vídeo do que nós estávamos fazendo, já para ter aquela ideia e voltar a estudar em casa. Então foi isso que eu fiz, voltei com o vídeo, observei, escutei bastante, vi a performance e comecei a treinar naquele novo tom. (ESTUDANTE 1, 26/10/2017).

Além do destaque para a escuta musical no smartphone dentro do processo de aprendizagem da música, destaco na fala apresentada a citação do Youtube como aplicativo de escuta musical e o aplicativo de cifras como apoio. Segundo a pesquisa apresentada por Henderson Filho e Medeiros (2017), a respeito dos aplicativos utilizados pelos estudantes do curso de Licenciatura em Música da UEPA para escutar música no smartphone:

[...] o mais citado foi o próprio reprodutor de música do celular (61\%). Contudo, 19\% dos respondentes citaram o Youtube como reprodutor utilizado, o que nos permite refletir a respeito do crescimento da música associada ao vídeo (ou clipes), pois o Youtube é um site de compartilhamento de vídeos que apesar de oferecer grande variedade destes, tem gerado considerável espaço para a música. (HENDERSON FILHO; MEDEIROS, 2017, p. 7, grifo nosso)

Segundo Cota (2016), esse aplicativo é:

[...] um grande palco onde os músicos podem expor suas ideias e criação. Ressalta-se ainda, que é capaz de realizar concertos em tempo real pelo Youtube. Essa possibilidade endossa o que lazzetta e Kon (1998) afirmaram sobre uma nova organização espaço-temporal, ou seja, o palco ou a sala de concertos passam a estar com as pessoas onde quer que elas estejam, desde que haja acesso à internet. (COTA, 2016, p. 306).

Henderson Filho e Medeiros (2017) afirmam ainda que:

O crescimento não ocorreu somente na relação entre música e vídeos, mas também na associação a letrase cifras. Cerca de $84,3 \%$ dos respondentes afirmaram associar a escuta musical à visualização simultânea de vídeos, cifras e/ou letras. (HENDERSON FILHO; MEDEIROS, 2017, p. 7, grifo nosso)

A Estudante 2 que está cursando o $4^{\circ}$ semestre do curso, afirmou ter utilizado a escuta musical na matéria "Prática em conjunto" e afirmou que "[...] às vezes usávamos na matéria de prática em conjunto, nós ouvíamos pra aprender música, pra aprender o arranjo, essas coisas". (ESTUDANTE 2, 27/10/2017).

Com o Estudante 3 que cursa o $6^{\circ}$ semestre, a escuta musical no smartphone ocorreu na matéria "Informática aplicada a música" e o mesmo afirma:

[...] nessa disciplina os alunos tem de fazer arranjos por meio de softwares. Para que isso ocorra é necessário escolher uma música, gravar separadamente os instrumentos e fazer as edições nos programas especializados. Todas essas tarefas são feitas através da escuta que às vezes ocorre por meio do smartphone [...] eu achei essa disciplina interessante [...] muitas vezes nós íamos fazer as edições das músicas queríamos fazer muitas vezes ao pé daquela, digamos assim, ao pé da letra, ouvíamos a música e queríamos fazer do mesmo jeito que estava lá [...] Alguns faziam improvisos, algumas mudanças, mas no meu caso, da minha equipe, nós ouvíamos muito pra perceber que horas entrava determinada batida da bateria, ou aquele contratempo, qual é, em que parte vai colocar ele, então, era a própria disciplina, ela exigia isso, essa, essa escuta da música que a gente estava trabalhando." (ESTUDANTE 3, 27/10/2017).

Quando perguntado aos mesmos se a escuta musical é incentivada pelo curso, professores ou ocorre de uma forma própria do aluno, os entrevistados 1 e 3 apresentaram concordância em 
suas falas em afirmar que há utilização por parte dos professores e que o estudante está inserido de forma significativa nesse uso. Para o Estudante 1 a escuta musical ocorre de forma intencional e não-intencional, e confirma haver a utilização da escuta musical por parte dos professores, no entanto os professores "não falavam pra nós 'façam o mesmo que eu', porém, todos nós víamos aquela situação, institivamente nós tentávamos fazer igual" (ESTUDANTE 1, 26/10/2017). A respeito do interesse do aluno, o entrevistado afirma: "[..] no segundo momento vem o interesse do próprio aluno [...], por exemplo, houveram muitos alunos que [...] não se interessavam e talvez tenham deixado de descobrir muitas coisas boas [...]". (ESTUDANTE 1, 26/10/2017).

O Estudante 3 afirma que os professores utilizam a escuta musical e incentivam a mesma, acredita e destaca que o trabalho da escuta musical deve ser buscado pelos estudantes apresentando o professor apenas como incentivador:

[...] os professores, eles já partem do pressuposto de que o aluno, ele já está tão inteirado com essa tecnologia que ele mesmo já acaba utilizando o smartphone para aquela disciplina [...] Ele mesmo, o aluno acaba utilizando, assim, entre aspas, por osmose, de tanto no dia-a-dia estar ali, utilizando aquilo [..] seja baixando uma música e compartilhando pra que todos possam ouvir, então acaba que o professor, ele lança a semente [...]. Muitos professores nossos fazem assim, eles colocavam a música [...] pra turma ouvir e muitas vezes indicava pra nós: "olha! Ouçam essa obra e essas daqui", e listavam [...] as obras que nós poderíamos, deveríamos ouvir, então acaba que nós íamos atrás e baixávamos essas músicas, essas obras, e ficávamos ouvindo, ou na nossa casa, ou no ambiente de trabalho, [...] geralmente o quê que eles faziam? [...] Eles (os professores) pegavam o equipamento de som, colocavam pra gente ouvir e após a escuta, muitas vezes eles repetiam, dando ênfase em determinados pedaços da música ou determinados trechos e davam a sugestão de ouvirmos mais obras daquele compositor [...] então eu vejo que eles utilizam sim." (ESTUDANTE 3, 27/10/2017).

A Estudante 2 declara a respeito do uso dos smartphones como plataforma de apoio que:

Eu acho que muitos dos professores, eles não estão muito atentos a isso, porque o celular hoje é uma coisa que é muito acessível, não é? E cabe ao professor mesmo, eu vejo assim, dessa forma, cabe ao professor mesmo perceber, "caramba, tu estás com o celular o tempo todo, então eu vou mandar alguma coisa aqui pra você aprender sabe, com o celular". Ele tá ali o tempo inteiro, você tá no ônibus, você tá no intervalo, em qualquer lugar você tá mexendo no celular e em qualquer lugar você pode estar aprendendo com celular, então cabe ao professor mesmo ter essa sacada, de ideia, de poder utilizar isso a favor. (ESTUDANTE 2, 27/10/2017).

O Curso de Licenciatura apresentou influência sobre a escuta dos alunos. Segundo os Estudantes 1 e 3 o curso possibilitou o contato com outros estilos musicais e compositores que os mesmos não haviam ouvido anteriormente. Para o Estudante 1 que não era acostumado a ouvir determinados gêneros de música declara que:

[...] Eu não era acostumado a ouvir e passei a ouvir depois que entrei no curso, por que nós encontramos muita gente que houve e que é legal, nós trabalhamos dentro do curso com isso, trabalhamos em prática em conjunto: brega, bossa, samba também, então isso tudo passa a fazer parte do nosso cotidiano. (ESTUDANTE 1, 26/10/2017).

O Estudante 3 destaca:

\begin{abstract}
Muitas músicas que eu comecei a ouvir recentemente foi depois de disciplinas que foram ministradas aqui: história da música, música popular brasileira [..] como eu te falei, eu gosto muito de música erudita e muitas músicas eruditas que eu comecei a ouvir recentemente são de compositores que eu nem sabia que existiam. Antigamente eu costumava ouvir Mozart, Haydn, Beethoven, Bach, mas com as disciplinas aqui na UEPa eu fui vendo outros compositores, de períodos mais recentes da história da música. Então, de uma certa forma influencia sim. (ESTUDANTE 3, 27/10/2017).
\end{abstract}

É possível observar com os comentários a relação de influência que o curso de licenciatura exerce sobre o repertório musical escutado por seus alunos. Nota-se que o curso possibilita o estreitamento do contato dos estudantes com diversos gêneros musicais através tanto da convivência com outros estudantes com gostos musicais diversos quanto pelo trabalho nas disciplinas.

\section{CONSIDERAÇÕES FINAIS}

O ponto de partida desta pesquisa foi a compreensão da evolução e transformação dos meios de gravação e reprodução sonora desde a invenção do fonógrafo até chegarmos ao smartphone, pois essa evolução impactou a forma de se produzir, comercializar e consumir música. Observamos que a atividade de ouvir música ocupa um lugar considerável na vida das pessoas e esse consumo é motivado atualmente 
pelas tecnologias móveis, que possibilitam a escuta musical em qualquer lugar. A pesquisa aqui apresentada teve como finalidade a compreensão do processo da escuta musical de jovens estudantes de música por meio de smartphones, pois a evolução tecnológica continua a afetar a relação do ouvinte com a música.

Os resultados apontam para o aumento do espaço significante que os smartphones tem na vida das pessoas, em destaque os estudantes de música. Através dos resultados podemos observar a respeito do 'porquê' os estudantes escutam mais música no smartphone do que em outros aparelhos, sendo este 'porquê' a acessibilidade/mobilidade, que nos remete aos "fatores determinantes do sucesso do celular" criados por Gonord e Menrath (2005 apud VICENTIN, 2008, p. 34).

Quanto à influência exercida pelo curso, é possível observar através das falas dos entrevistados que o curso de licenciatura exerce sobre o repertório musical escutado por seus alunos uma influência significante. Nota-se que o curso possibilita o estreitamento do contato dos estudantes com diversos gêneros musicais através tanto da convivência com outros estudantes com gostos musicais diversos quanto pelo trabalho nas disciplinas, como Prática em Conjunto.

Sobre as funções da escuta musical em smartphones, os resultados apresentaram três funções: aprender, apreciar (aspecto sonoro) e relaxar (função de expressão emocional). 0 aprender está relacionado com o ato de escutar uma música e através dessa escuta trabalhar o aprendizado e execução de padrões e expressões musicais, parâmetros sonoros entre outros. 0 apreciar está diretamente ligado ao som, aos aspectos sonoros, que segundo Santos (2007) são "[...] referentes às qualidades intrínsecas do som - timbre, densidade, altura, intensidade - e da música - ritmo, melodia, harmonia, andamento" (SANTOS, 2007, p. 71). Já o relaxar se configura como função de expressão emocional (SANTOS, 2007), essa função consiste na ideia de que a expressão e o extravasamento de ideias e emoções fazem parte da música.

Os resultados apontam ainda para a forma como os estudantes utilizam a escuta musical em atividades de aprendizagem: o Estudante
1 utiliza para aprender músicas que serão executadas em seu trabalho como músico baterista, a Estudante 2 utiliza para aprender e observar técnicas tanto de cantores como instrumentistas. Já o Estudante 3 fez utilização para aprender músicas em inglês trabalhando a pronúncia da língua nas músicas.

Quanto à relação da escuta musical com a formação recebida no curso de Licenciatura em Música da UEPA, todos os entrevistados afirmaram já ter utilizado a escuta musical para alguma matéria do curso e afirmam receberem influências do curso sobre a escuta musical. Para os Estudantes 1 e 3 o curso possibilitou o contato com outros estilos musicais e compositores que os mesmos não haviam ouvido anteriormente. Quando indagados a respeito do incentivo à escuta musical, os Estudante 1 e 2 afirmaram não receber incentivo do curso, para o Estudante 1 "o curso em si ele ainda carece de muita mudança pra que isso seja um fator ocorrente. [...] as ferramentas do curso são muito [...] fracas (ESTUDANTE 1, 26/10/2017). Os Estudantes 1 e 3 concordaram que o incentivo vem mais por parte dos professores e destacam que o aluno deve ter iniciativa e não apenas esperar pelo professor.

Sendo de conhecimento geral que a formação do professor é um processo de contínua construção, tomo como base esta pesquisa e proponho que a escuta musical seja mais explorada dentro do ensino superior, tendo em vista que os acadêmicos de música têm uma relação estreita com a mesma, sendo assim a atividade de escuta musical deve ser fortalecida dentro da formação do futuro professor.

Para Teixeira (2016): “O aprendizado não acontece [...] só na sala de aula, ele também ocorre em qualquer lugar. O professor deve incentivar a prática do aprendizado fora da escola, e os smartphones [...] podem ser considerados como ferramentas para que isso aconteça." (TEIXEIRA, 2016, p. 7).

O smartphone trata-se de um recurso em potencial para apoiar o aprendizado musical, mas ainda pouco explorado por professores nos cursos superiores de música, entretanto Freitas e Lima (2010) afirmam que não é somente utilizar as tecnologias para que o processo de aprendizagem ocorra de forma consistente, é necessário saber usar de forma pedagógica a tecnologia escolhida. 


\section{REFERÊNCIAS}

COTA, Denis Martino. O youtube e os dispositivos móveis como agentes transformadores da interação com a música. Anais [do] IVSimpósio Brasileiro De Pós-Graduandos Em Música, 4., 2016, Rio de Janeiro: SIMPOM, p. 304 a 311, 2016.

FREITAS, R. V.; LIMA, M. S. S. As Novas Tecnologias na Educação: Desafios Atuais Para a Prática Docente. In: IV Colóquio Internacional Educação e Contemporaneidade, 2010, São Cristóvão. Anais eletrônicos do IV Colóquio Internacional Educação e Contemporaneidade. São Cristóvão, 2010.

GOMES, Rodrigo M. Do fonógrafo ao MP3: Algumas Reflexões sobre Música e Tecnologia.

Revista Brasileira de Estudos da Canção. Natal, n. 5, p. 73 a 82, 2014.

HENDERSON FILHO, José Ruy. Música Smart: um estudo etnográfico sobre a escuta musical em dispositivos móveis. Anais [do] II Encontro Regional da Associação Brasileira de Etnomusicologia [e] II Colóquio Amazônico de Etnomusicologia. Belém, PA. p. 299 - 304. jun. 22-24, 2016.

HENDERSON FILHO, José Ruy; MEDEIROS, Juliana do Rêgo. Música mobile: um estudo sobre a escuta musical de estudantes de música em smartphones.

Anais [do] XXIII Congresso Nacional da Associação Brasileira de Educação Musical. Manaus, AM. 16-20 de outubro. 11 p. 2017.

MARTINS, Gilberto de Andrade; THEÓPHILO, Carlos Renato. Metodologia da Investigação Científica para Ciências Sociais Aplicadas. 2. ed. São Paulo: Atlas, 2009.

MERIJE, Wagner. Mobimento: educação e comunicação mobile. São Paulo: Pirenópolis, 2012.

SANTOS, Cleonice dos. Preferências musicais de alunos de $5^{a}$. A $8^{a}$ série da rede municipal de ensino de Curitiba. "Significados da escuta". Dissertação (Mestrado em Educação) - Universidade Federal do Pará, Curitiba, 2007.

SILVA, Helena Lopes da; BARBOSA, Rogério Vasconcelos. Escuta (cria)tiva: Propostas para o desenvolvimento da escuta musical na educação básica. Foro de Educación, v. 15, n. 22, enerojunio / janeiro-junho, Cabrerizos - España, 2017.
TEIXEIRA, Pedro Henrique Araujo. A utilização de aplicativos musicais para smartphones e tablets com sistema operacional android como forma de auxílio para professores de música. 2016. Trabalho de conclusão de curso (Graduação) - Universidade do Estado do Pará, Belém - PA, 2016.

VICENTIN, Diego Jair. A mobilidade como artigo de consumo. Apontamento sobre as relações com o aparelho celular. 2008. $159 \mathrm{f}$. Dissertação (Mestrado em Sociologia) - Instituto de Filosofia e Ciências Humanas da Universidade Estadual de Campinas, 2008.

\section{SOBRE OS AUTORES}

José Ruy Henderson Filho é Doutor em Música (área de concentração: Educação Musical) pela Universidade Federal do Rio Grande do Sul, mestre em Ciências da Computação pela Universidade Federal de Santa Catarina (2002), especialista em Informação na Educação (1998) e licenciado em Música (1995) pela Universidade do Estado do Pará. Professor Adjunto da Universidade do Estado do Pará. Coordenador institucional do PIBID/UEPA desde 2011. Tem experiência na área de Música, com ênfase em Educação Musical, atuando principalmente nos seguintes temas: formação de professores, educação online, educação musical, música no Pará e música e tecnologia.

Juliana do Rêgo Medeiros é Graduanda do curso de Licenciatura em Música da UEPA -Universidade do Estado do Pará, estudante do curso Técnico em Música no Instituto Estadual Carlos Gomes com habilitação em Flauta doce, integrante do Grupo de Estudo e Pesquisa em Música - GEPEM e Bolsista PIBIC - Iniciação Científica. 